\title{
Investigation of IgG and IgM Antibodies Against Toxoplasma gondii Among Diabetic Patients
}

\author{
Mohammad Jafari Modrek ${ }^{1,2}$; Ramin Saravani ${ }^{3,4,}$; Mohammad Mousavi ${ }^{1,2}$; Alireza Salimi \\ Khorashad $^{1,2} ;$ Maryam Piri $^{5}$ \\ 1 Infectious Disease and Tropical Medicine Research Center, Zahedan, IR Iran \\ ${ }^{2}$ Department of Medical Parasitology, Zahedan University of Medical Sciences, Zahedan, IR Iran \\ ${ }^{3}$ Cellular and Molecular Research Center, Zahedan, IR Iran \\ 4 Department of Clinical Biochemistry, Zahedan University of Medical Sciences, Zahedan, IR Iran \\ 5 Diabetes Center, Ali Asghar Hospital, Zahedan University of Medical Sciences, Zahedan, IR Iran \\ *Corresponding author: Ramin Saravani, Cellular and Molecular Research Center, Zahedan, IR Iran. Tel: +98-543329892, Fax: +98-543329892, E-mail: saravaniramin@yahoo.com
}

Received: February 2, 2015; Revised: February 10, 2015; Accepted: February 21, 2015

\begin{abstract}
Background: Toxoplasma gondii is an important opportunistic parasite in immunocompromised people. On the other hand, diabetes is a systemic disease which affects the immune system and minimizes cellular and humoral immunity and thus diabetic patients have an increased susceptibility to protean infections.

Objectives: The aim of the current study was to determine the serum levels of toxoplasma antibodies in diabetic patients.

Patients and Methods: In this cross-sectional study, 205 serum samples were collected from diabetic patients referred to diabetes center in Ali Asghar Hospital in Zahedan (southeastern Iran). We evaluated the levels of IgG and IgM antibodies against T. gondii in the patients' sera using the Enzyme-Linked Immunosorbent Assay.

Results: A total of 205 blood samples obtained from diabetic patients ( 42 men and 163 women with age range 13 - 60 years) were examined for the presence of toxoplasma antibodies. Among patients, 60 cases (29.3\%) were seronegative and 145 patients (70.7\%) were seropositive, included 53.145 (36.6\%) (IgG+, IgM+) acute phase, 72.145 (49.6\%) (IgG+, IgM-) chronic phase and 20.145 (13.8\%) (IgG-, IgM+) false positive. The relationship between diabetes and toxoplasmosis was evaluated using the chi-square test $(\mathrm{P}<0.05)$. The difference between age, gender, meat consumption, Fasting Blood Sugar(FBS) and the presence of toxoplasma antibodies was statistically significant $(\mathrm{P}<0.05)$. There was no relation between optical disease and abortion with infection. The highest seroprevalence rate of T. gondii IgM and IgG antibodies was observed in the group of women.

Conclusions: Diabetes and consumption of half-cooked meats increase the chance of toxoplasmosis. Thus, it is recommended to study the serum level of antibodies against toxoplasmosis in diabetic patients and repeat it periodically.
\end{abstract}

Keywords: Diabetes Mellitus; Toxoplasma; ELISA; IgG; IgM

\section{Background}

Toxoplasma gondii is an obligate intracellular protozoan parasite, capable of infecting all warm-blooded animals, and can cause a severe disease in pregnant women and immunocompromised individuals. It can take several different forms: the oocyst, the tachyzoite and the cyst $(1,2)$. Primary infection is usually subclinical but sometimes leads to chorioretinitis, or may damage the fetus if acquired during pregnancy (3). Diabetes like Human Immunodeficiency Virus (HIV) or other immunodeficiency disorders can lead to opportunistic infections. There are several reports demonstrating that diabetic patients have an increased susceptibility to many specific infections such as toxoplasmosis $(1,4,5)$. Other infections also occur with increased severity and are associated with an increased risk of complications in patients with diabetes $(4,5)$. Animals and humans are intermediate hosts for replication of $T$. gondii. Humans are infected via con- taminated water, half-cooked meat and vegetables that are not disinfected. Parasites will proliferate within the host cells lysing them, eventually. They can disseminate through the body via blood circulation and infect any cells. Fetus through the placenta of infected mothers can acquire infection (6). Severe clinical signs in the infected infant are more commonly observed in offspring of women whose infection was acquired in the early of gestation. In the case of infection in the first trimester of pregnancy, incidence of transplacental transmission is low (15\%), but the disease can be severe in neonate. When infection occurs in third trimester, incidence of transplacental infection is high (65\%); however, infant is usually asymptomatic at birth. Therefore, early and accurate diagnosis of toxoplasmosis can make an important contribution to the prevention and control of the disease, especially in people who are at risk (6). Many serological tests

Copyright (C) 2015, Infectious Diseases and Tropical Medicine Research Center. This is an open-access article distributed under the terms of the Creative Commons Attribution-NonCommercial 4.0 International License (http://creativecommons.org/licenses/by-nc/4.0/) which permits copy and redistribute the material just in noncommercial usages, provided the original work is properly cited. 
including the latex agglutination test, Enzyme-Linked Immunosorbent Assay (ELISA), Indirect Fluorescence Antibody (IFA) and hemagglutination tests have been used in the detection of antibodies against T. gondii (7). Diabetes Mellitus (DM) is one of the most important diseases in the world and accounts for $90 \%$ of cases of diabetes globally (8). According to the America Diabetes Association (ADA) diabetes were divided into two types: type 1 and type 2 . Type 1 juvenile diabetes is known to be often acute insulin-dependent and more likely to present with diabetic ketoacidosis. But, patients with type 2 diabetes are not susceptible to ketoacidosis and insulin concentrations around a reference value or more of the range can be observed, but they are insulin resistant. Obesity is associated with the disease and most people in the age of 40 years suffer from this disease and the affected organs of their body are damaged (8). In type 2 diabetes, often as a result of obesity, deficiency in insulin secretion occurs (8). In the acute phase of toxoplasmosis, $80 \%$ of healthy hosts are without clinical symptoms. Only $20 \%$ of people, including children and adults show signs and symptoms of infection. Parasite tissue cysts in hosts such as lung, liver, spleen, heart and pancreas may contribute to maintenance of immunity against reinfection (9). When individuals become immunocompromised, the latent infection can progress and led to a severe disease. Several clinical cases have been reported in diabetic patients such as central nervous system toxoplasmosis and congenital toxoplasmosis $(10,11)$. Totally, the percentage of serological positive cases was found to increase with increasing age and usually after the age of 25 in both genders are the same (12). The seroprevalence rates of toxoplasma antibodies have a wide range as follows: Brazil $66.3 \%$ (13) India 49.52 \% (14), Thailand $28.3 \%$ (15), Turkey 49.4\% (16), and France 43.8\% (17). Obvious differences in the prevalence rates of toxoplasmosis in different areas are because of geographical climate, diet, and alimentary habits. In dry areas, toxoplasmosis is less prevalent than in hot and damp areas (18).

\section{Objectives}

The purpose of this study was to investigate the presence of specific antibodies against $T$. gondii infection among people with diabetes in Zahedan, southeast of Iran, using the ELISA method.

\section{Patients and Methods}

\subsection{Selection of Patients}

This cross-sectional study was performed on diabetic patients referred to diabetes center of Ali Asghar Hospital in Zahedan (southeastof Iran) during six months, from July 2014 to January 2015. All patients who were referred to the diabetes center and would like to contribute in our study were questioned about demographic characteristics, abortion (for women), cooking and consumption of meat and ocular discomfort. Medical examination was done by a general practitioner who evaluated diabetic patients in this center. To confirm the diagnosis of diabetes, biochemistry tests such as hemoglobin A1C (Hb A1C), Fasting Blood Sugar (FBS), and sulfo-salicylic acid test (3\%) (to detect urine protein) were measured in the Ali Asghar laboratory. Two hundred and fifty patients regardless of the type of diabetes had been evaluated during 6 months. For serological tests, two mL of blood sample was collected without EDTA anticoagulant. All tubes centrifuged at $3500-4000 \mathrm{rpm}$ for five minutes. Serum samples were kept at $-20^{\circ} \mathrm{C}$ until the start of the experiments.

\subsection{An Enzyme-Linked Immunosorbent Assay}

In this study, serum samples were analyzed for IgG and IgM antibodies by ELISA method using available kits (EIA3519 and 3520, DRG instrument GmbH, Germany). Briefly, one of the wells of the plate ELISA kit as blank considers. Next were added $100 \mu \mathrm{L}$ of standards, positive, negative controls and samples into selected wells plates. The wells were incubated for 60 minutes at room temperature. At the end of 60 minutes, the contents of the wells were drained and then washed 5 times with wash solution. Except the blank well, $100 \mu \mathrm{L}$ of the enzyme conjugate was added into each well and incubated for 30 minutes at room temperature. Then, contents of the wells were emptied and the wash cycle was repeated. To all wells, $100 \mu \mathrm{L}$ of TMB (tetra methyl blue) substrate solution was added and incubated for exactly 15 minutes at room temperature in the dark. For stopping the reaction $100 \mu \mathrm{L}$ of stop solution was added. Absorbance plate wells were read at a wavelength of $450-620 \mathrm{~nm}$ with a plate reader within 30 minutes. To calculate the mean absorbance values, all samples were duplicated. For interpretation of quantitative results in this study, IgG antibody levels greater than 14.5 IU/mL were positive. Toxoplasma IgM antibodies were detected in subject's diabetic IgG positive and levels more than $1.1 \mathrm{UL} / \mathrm{mL}$ was considered positive. Chronic toxoplasmosis, including IgG+ and IgM- and positive IgG and IgM were determined as an acute toxoplasmosis.

\subsection{Data Analysis}

Data were analyzed using SPSS software (version 18). The chi-squared and Fisher's exact tests were used to compare the seroprevalence values, related to the characteristics of the subjects. $\mathrm{P}<0.05$ was considered as the level of significance.

\section{Results}

two hundred and five patients with diabetes (42 men and 163 women, the mean age of $13-<60$ years and mean \pm SD of $53.4 \pm 13.32$ ) were included in our study. Their serum samples were analyzed for T. gondii IgG and IgM antibodies using the ELISA method. The results showed that 60 (205) patients (29.3\%) were seronegative and 145/205 (70.7\%) were seropositive including 53/145 (36.6\%) (IgG+, 
IgM+) with acute phase, $72 / 145$ (49.6\%) (IgG+, IgM-) chronic phase and 20/145 (13.8\%) (IgG-, IgM+) false positive. We considered IgG- and IgM+ false positive according to Liesenfeld study; if the IgG is negative and the IgM is positive, the IgM result should be considered to be a false positive and the patient should be considered to be not infected (19). A positive IgG and IgM toxoplasmosis was observed in $61 \%$ and $35.6 \%$ of diabetic patients, respectively (Table 1).

Overall, 163 cases (79.5\%) were female and 42 cases (20.5\%) were male. There was a significant difference between gender (female) and toxoplasmosis $(\mathrm{P}<0.05)$.
Among 169 women, 69 cases (42.3\%) had a history of abortion and 94 cases (57.7\%) did not have (Table 2 ). The results showed that 131 patients had fasting blood glucose levels between 121 - $300 \mathrm{mg} / \mathrm{dL}$ (Table 3). Also, there was a significant difference between FBS between 121 - $300 \mathrm{mg} /$ $\mathrm{dL}$ and the presence of toxoplasma antibodies $(\mathrm{P}<0.05)$. Patients were divided into three age groups, including 12 - 30 years, 31 - 60 and more than 60 years. There was a statistically significant relationship between patients with age 31 - 60 years and presence of antibodies. Also, 43.9\% $(\mathrm{n}=90)$ of the patients had consumed half-cooked meat, which was statistically significant.

Table 1. Prevalence of Antibodies IgG and IgM Anti-Toxoplasma gondii Among Studied Individuals a

\begin{tabular}{lccc}
\hline Antibody & Positive & Negative & P Value \\
\hline IgG & $125(61)$ & $80(39)$ & 0.015 \\
IgM & $73(35.6)$ & $132(64.4)$ & \\
\hline a Data are presented as\%. & & &
\end{tabular}

Table 2. Demographic Characteristics of Patients With Diabetes and Seropositivity of Toxoplasma Gondii a,b

\begin{tabular}{|c|c|c|c|c|}
\hline \multirow[t]{2}{*}{ Characteristics } & \multirow[t]{2}{*}{ Frequency } & \multicolumn{2}{|c|}{ Diabetic with Anti-T. gondii } & \multirow[t]{2}{*}{ P Value } \\
\hline & & IgG+ & IgM+ & \\
\hline Gender & & & & 0.034 \\
\hline Male & $42(20.5)$ & $25(20)$ & $11(15.1)$ & \\
\hline Female & $163(79.5)$ & $100(80)$ & $62(84.9)$ & \\
\hline Age group, y & & & & 0.008 \\
\hline $13-30$ & $9(4.4)$ & $4(3.2)$ & $2(2.7)$ & \\
\hline $31-60$ & $139(67.8)$ & $84(67.2)$ & $52(71.3)$ & \\
\hline$>60$ & $57(27.8)$ & $37(29.60)$ & $19(26)$ & \\
\hline Optical Disease & & & & 0.91 \\
\hline Have & $35(47.9)$ & $53(42.4)$ & $35(47.9)$ & \\
\hline Don't have & $38(51.2)$ & $72(57.6)$ & $38(52.1)$ & \\
\hline Abortion & & & & 0.075 \\
\hline Have & $78(38)$ & $46(36.8)$ & $28(38.4)$ & \\
\hline Don't have & $127(62)$ & $79(63.2)$ & $45(61.6)$ & \\
\hline Meat Consumption & & & & 0.016 \\
\hline Half-Cooked & $90(43.9)$ & $55(44)$ & $38(52.1)$ & \\
\hline Boiled & $34(16.6)$ & $25(20)$ & $14(19.2)$ & \\
\hline Cooked & $81(39.5)$ & $45(36)$ & $21(28.8)$ & \\
\hline
\end{tabular}

a $\mathrm{P}<0.05$ was considered as statistically significance.

b Data are presented as No. (\%).

Table 3. Glucose Level and Toxoplasmosis Infection ${ }^{a}$

\begin{tabular}{lcc}
\hline Glucose Levels $(\mathbf{m g} / \mathbf{d L})$ & \multicolumn{2}{c}{ + Toxoplasmosis } \\
\cline { 2 - 3 } & IgG+ & IgM+ \\
\hline $\mathbf{6 0 - 1 2 0}$ & $31(24.8)$ & $16(21.9)$ \\
$\mathbf{1 2 1 - 3 0 0}$ & $79(63.2)$ & $52(71.3)$ \\
$>\mathbf{3 0 0}$ & $15(12)$ & $5(6.8)$ \\
Total & $125(100)$ & $73(100)$ \\
\hline
\end{tabular}

a Data are presented as No. (\%). 


\section{Discussion}

The prevalence rates of diabetes and toxoplasmosis are high in Iran $(4,20)$ and many countries around the world $(5,13-17)$. Considering this and also the importance of the complications and impairment of the cellular and humoral immunity resulted from diabetes, this study aimed to investigate the serum levels of toxoplasma antibodies in diabetic people for the first time in Zahedan, southeast of Iran. The results of the present study showed that 145 cases (70.3\%) among 205 diabetic subjects were seropositive. The results were higher than Shirbazou and Gocke studies. Shirbazou and colleagues showed that $60 \%$ of diabetic patients had specific IgG antibody against T. gondii (4) and $56 \%$ of diabetic patients in Gokce study were positive for $\operatorname{IgG}(5)$. There are a number of factors such as duration of diabetes, severity of noninfectious complications, abortion, optical disease, comorbidity, coinfection and meat consumption which can lead to acute infection in diabetic patients and also severe complications of disease. The highest seroprevalence rate of T. gondii IgM and IgG antibodies was observed in the women of old age. This is in accordance with the data obtained from previous studies carried out in different geographical settings $(21,22)$. This may be an indicator of high infection risk at early adolescences; also, older individuals have higher susceptibility to be exposed to many risk factors for T. gondii infection during their lives than younger individuals. As a result, a statistically significant correlation was found between the age and toxoplasmosis. These results were in accordance with the results of Sarkari study (23). Experimental studies had shown the presence of necrotic lesions and disseminated inflammation in various organs $(20,24,25)$. Tissue staining has frequently confirmed the presence of tachyzoites in these lesions. Furthermore, in a human study, a patient's death due to acute toxoplasmosis pancreatitis has been reported. Involvement of pancreas by disseminated toxoplasmosis has been described in other studies on diagnostic pathology and clinical correlations of parasitic infections $(20,24,25)$. Immunocompromised hosts, especially those with deficient cellular immunity, are at risk of reactivation of the chronic infection and dissemination, with the occurrence of fulminating disease like as sometimes reported in diabetic patients (11). Immunocompromised persons such as human immunodeficiency virus-infected individuals, organ transplant recipients, and patients with cancer are particularly susceptible to toxoplasma infections (7). The most frequent protozoan causing opportunistic infections in immunocompromised individuals is T. gondii Infection in humans usually occurs via consumption of cysts in undercooked meat. A significant decline in toxoplasma seroprevalence has been reported in many developed countries during the last decades and this phenomenon has been attributed to the introduction of modern farming systems resulting in a lower prevalence of toxoplasma cysts in meat with an increased use of frozen meat by consumers, which decreases the number of cysts in the meat $(26,27)$. In this area (Sistan and Baluch Province) due to consumption of infected meat (not well-cooked) and hygiene failure, we observe an increased rate of infection in the population. Our research found that there was a significant relationship between the consumption of half-cooked meats and toxoplasmosis in the population studied. The high prevalence of toxoplasma antibodies can be rooted in the culture of some people who would like to eat half-cooked meats in the form of grilled, especially in Balouch race. Since the course of toxoplasmosis cannot be fully controlled in diabetes patients, it is suggested to study the serum level of antibodies against toxoplasmosis in this group of patients and repeat it periodically.

\section{Acknowledgements}

This study was approved and supported by infectious and tropical disease center, Zahedan University of Medical Sciences, Zahedan, Iran.

\section{Authors' Contributions}

Study concept and design: Dr. Ramin Saravani and Dr. Mohammad Jafari Modrek. Acquisition of data: Dr. Ramin Saravani, Mohammad Mousavi and Dr. Maryam Piri. Analysis and interpretation of data: Dr. Ramin Saravani, Dr. Mohammad Jafari Madrak, Mohammad Mousavi and Alireza Salimi Khorashad. Drafting of the manuscript: All of authors. Critical revision of the manuscript for important intellectual content: All of the authors. Statistical analysis: Dr. Ramin Saravani and Mohammad Mousavi. Administrative, technical, and material support: Dr. Ramin Saravani and Mohammad Mousavi.

\section{Funding/Support}

This study was approved and supported by infectious and tropical disease center at Zahedan University of Medical Sciences, Zahedan. IR Iran.

\section{References}

1. Carruthers VB. Host cell invasion by the opportunistic pathogen Toxoplasma gondii. Acta Trop. 2002;81(2):111-22.

2. Montoya JG, Liesenfeld O. Toxoplasmosis. Lancet. 2004; 363(9425):1965-76.

3. Webster JP, Kaushik M, Bristow GC, McConkey GA. Toxoplasma gondii infection, from predation to schizophrenia: can animal behaviour help us understand human behaviour? J Exp Biol. 2013;216(Pt 1):99-112.

4. Shirbazou S, Delpisheh A, Mokhetari R, Tavakoli G. Serologic Detection of Anti Toxoplasma gondii Infection in Diabetic Patients. Iran Red Crescent Med J. 2013;15(8):701-3.

5. Gokce C, Yazar S, Bayram F, Gundogan K, Yaman O, Sahin I. AntiToxoplasma gondii antibodies in type 2 diabetes. Natl Med J India. 2008;21(1):51.

6. Kijlstra A, Jongert E. Control of the risk of human toxoplasmosis transmitted by meat. Int J Parasitol. 2008;38(12):1359-70.

7. Casartelli-Alves L, Boechat VC, Macedo-Couto R, Ferreira LC, Nicolau JL, Neves LB, et al. Sensitivity and specificity of serological tests, histopathology and immunohistochemistry for detection 
of Toxoplasma gondii infection in domestic chickens. Vet Parasitol. 2014;204(3-4):346-51.

8. Bertoldi AD, Kanavos P, Franca GV, Carraro A, Tejada CA, Hallal PC et al. Epidemiology, management, complications and costs associated with type 2 diabetes in Brazil: a comprehensive literature review. Global Health. 2013;9:62.

9. Silveira C, Vallochi AL, Rodrigues da Silva U, Muccioli C, Holland GN, Nussenblatt RB, et al. Toxoplasma gondii in the peripheral blood of patients with acute and chronic toxoplasmosis. BrJOphthalmol. 2011;95(3):396-400.

10. Yamakawa R, Yamashita Y, Yano A, Morita J, Kato H. Congenital toxoplasmosis complicated by central diabetes insipidus in an infant with Down syndrome. Brain Dev. 1996;18(1):75-7.

11. Cavallazzi LO. [Toxoplasmosis of the central nervous system in a diabetic patient]. Arq Neuropsiquiatr. 1985;43(3):319-21.

12. Bellali H, Pelloux H, Villena I, Fricker-Hidalgo H, Le Strat Y, Goulet V. Prevalence of toxoplasmosis in France in 1998: is there a difference between men and women? At what age do children become infected? Rev Epidemiol Sante Publique. 2013;61(4):311-7.

13. Barbosa IR, de Carvalho Xavier Holanda CM, de Andrade-Neto VF. Toxoplasmosis screening and risk factors amongst pregnant females in Natal, northeastern Brazil. Trans R Soc Trop Med Hyg. 2009;103(4):377-82.

14. Sarkar MD, Anuradha B, Sharma N, Roy RN. Seropositivity of toxoplasmosis in antenatal women with bad obstetric history in a tertiary-care hospital of Andhra Pradesh, India. J Health Popul Nutr. 2012;30(1):87-92.

15. Nissapatorn V, Suwanrath C, Sawangjaroen N, Ling LY, Chandeying V. Toxoplasmosis-serological evidence and associated risk factors among pregnant women in southern Thailand. Am J Trop Med Hyg. 2011;85(2):243-7.

16. Al-Mendalawi MD. The investigation of congenital toxoplasmosis in a tertiary care hospital in Turkey. Saudi Med J. 2010;31(1):96.

17. Berger F, Goulet V, Le Strat Y, Desenclos JC. Toxoplasmosis among pregnant women in France: risk factors and change of prevalence between 1995 and 2003. Rev Epidemiol Sante Publique. 2009;57(4):241-8.
18. Cantella R, Colichon A, Lopez L, Wu C, Goldfarb A, Cuadra E, et al. Toxoplasmosis in Peru. Geographic prevalence of Toxoplasma gondii antibodies in Peru studied by indirect fluorescent antibody technique. Trop Geogr Med.1974;26(2):204-9.

19. Liesenfeld O, Press C, Montoya JG, Gill R, Isaac-Renton JL, Hedman K, et al. False-positive results in immunoglobulin M (IgM) toxoplasma antibody tests and importance of confirmatory testing: the Platelia Toxo IgM test. J Clin Microbiol. 1997;35(1):174-8.

20. Siyadatpanah A, Tabatabaie F, Oormazdi H, Reza A, Meamar ER, Hadighi R, et al. Comparison of anti-toxoplasma IgG and IgM antibodies determined by ELISA method in diabetic and non-diabetic individuals in west Mazandaran province, Iran, 2011-2012. Ann Biol Res. 2013;4(6):281-5.

21. Han K, Shin DW, Lee TY, Lee YH. Seroprevalence of Toxoplasma gondii infection and risk factors associated with seropositivity of pregnant women in Korea.J Parasitol. 2008;94(4):963-5.

22. Zemene E, Yewhalaw D, Abera S, Belay T, Samuel A, Zeynudin A. Seroprevalence of Toxoplasma gondii and associated risk factors among pregnant women in Jimma town, Southwestern Ethiopia. BMC Infect Dis. 2012;12:337.

23. Sarkari B, Shafiei R, Zare M, Sohrabpour S, Kasraian L. Seroprevalence and molecular diagnosis of Toxoplasma gondii infection among blood donors in southern Iran. J Infect Dev Ctries. 2014;8(4):543-7.

24. Waree P, Ferguson DJ, Pongponratn E, Chaisri U, Sukthana Y. Immunohistochemical study of acute and chronic toxoplasmosis in experimentally infected mice. Southeast Asian J Trop Med Public Health. 2007;38(2):223-31.

25. Hofgartner WT, Swanzy SR, Bacina RM, Condon J, Gupta M, Matlock PE, et al. Detection of immunoglobulin G (IgG) and IgM antibodies to Toxoplasma gondii: evaluation of four commercial immunoassay systems. J Clin Microbiol. 1997;35(12):3313-5.

26. Tenter AM, Heckeroth AR, Weiss LM. Toxoplasma gondii: from animals to humans. Int J Parasitol. 2000;30(12-13):1217-58.

27. Dubey JP, Jones JL. Toxoplasma gondii infection in humans and animals in the United States. Int J Parasitol. 2008;38(11):1257-78. 